\title{
Effects of Withania coagulans extract and morphine on spermatogenesis in rats
}

\author{
Ali Noori ${ }^{1 *}$, Leila Amjad ${ }^{1}$, Fereshteh Yazdani ${ }^{2}$ \\ ${ }^{1}$ Department of Biology, ${ }^{2}$ Young Researchers and Elite Club, Falavarjan Branch, Islamic Azad University, Isfahan, Iran \\ *For correspondence: Email: ali.noori55@gmail.com; Tel: +98-913169918; Fax: +98-0381-3330709
}

Sent for review: 25 September 2017

Revised accepted: 11 March 2019

\begin{abstract}
Purpose: To investigate the comparative effects of Withania coagolans extract and morphine on spermatogenesis in rats

Methods: W. coagolans was collected from Sistan and Baluchestan, Iran and 50 and $100 \mathrm{mg} / \mathrm{kg}$ body weight doses of methanol extract and 5,10 and $15 \mathrm{mg} / \mathrm{kg}$ body weight doses of morphine were administered parenterally to the rats which were divided into groups. Blood samples were collected and the levels of luteinizing hormone (LH), follicle stimulating hormone (FSH), and testosterone were assayed. The testicular tissue was isolated for histopathological examination.

Results: No significant changes were observed in levels of $L H, F S H$ and testosterone in treated groups $(p<0.05)$. However, there was significant difference between the treated groups for extract plus morphine groups, in terms of the number of spermatogonium, spermatocytes and spermatide variation. Moreover, the results indicate tissue disorders in all groups relative to control. The extract caused more disturbances in spermatogenesis compared to morphine, and appears to improve parameters related to spermatogenesis.

Conclusion: The results show that the higher dose of Withania coagolans extract (100 mg/kg) exerts varying effects on reproductive parameters. Moreover, the lower dose of Withania coagolans extract (50 $\mathrm{mg} / \mathrm{kg}$ ) enhanced spermatogenesis while also protecting against the damaging effects of morphine.
\end{abstract}

Keywords: Morphine, Spermatogenesis, Spermatogonium, Spermatide, Spermatocyte, Withania coagolans

\begin{abstract}
This is an Open Access article that uses a fund-ing model which does not charge readers or their institutions for access and distributed under the terms of the Creative Commons Attribution License (http://creativecommons.org/licenses/by/4.0) and the Budapest Open Access Initiative (http://www.budapestopenaccessinitiative.org/read), which permit unrestricted use, distribution, and reproduction in any medium, provided the original work is properly credited.
\end{abstract}

Tropical Journal of Pharmaceutical Research is indexed by Science Citation Index (SciSearch), Scopus, International Pharmaceutical Abstract, Chemical Abstracts, Embase, Index Copernicus, EBSCO, African Index Medicus, JournalSeek, Journal Citation Reports/Science Edition, Directory of Open Access Journals (DOAJ), African Journal Online, Bioline International, Open-J-Gate and Pharmacy Abstracts

\section{INTRODUCTION}

Addiction is a reversible chronic disorder that is spreading among different communities around the world [1]. Opium comes from Papaver rhoeas, which includes at least 20 alkaloids, one of which is morphine alkaloids. Opium acts through drug receptors. These receptors are dispersed in limbic system, thalamus and hypothalamus, also, their function includes hypophysis secretions in the testis [2]. Morphine is used clinically to control severe pain, however, it has many side effects, such as vomiting, nausea, constipation, tolerance, and dependence [2]. Moreover, morphine reduces stages of spermatogenesis through inhibiting luteinizing hormone (LH). Male fertility requires normal spermatogenesis. 
$\mathrm{LH}$ and follicle-stimulating hormone (FSH) are involved in the endocrine mechanism through act on the testosterone testosterone produced by the leydig cells [3]. Thus, a combination of testosterone, LH and FSH activity are needed for stimulating spermatogenesis. $\mathrm{LH}$ and $\mathrm{FSH}$ are glycoprotein hormones, called gonadotropins, that modulate gonadal functions [4]. LH affects on leydig cells and causes to produce testis steroids. On the other hand, FSH is the main motivator for growth of testis seminiferous tubules [5]. Moreover, spermatogenesis depends on the function of testosterone that is required for initiating spermatogenesis at maturity and the maintenance of this process in the adult [6].

With regard to the harmful effects of chemical drugs for the treatment of addiction, the use of herbal medicines is considered [1]. Withania coagulans Dual. belongs to family Solanaceae. This plant is a general medicinal plant in many parts of Indai and Pakistan. Phytochemical research of the $W$. coagulans aqueous and methanol fruits extracts showed the presence of alkaloids, steroids, phenolic compounds, tannins, saponins, carbohydrates, proteins, amino acids and organic acids [7]. This plant is rich in withanolide that is a group of alkaloids. The investigation on $W$. coagulans revealed that it known as to treatment of ulcers, rheumatism bronchitis, nervous exhaustion, disability, insomnia, failure in children thrive and impotence [7]. With regard to the harmful effects of morphine on spermatogenesis the aim of this study was therefore to compare the effects of $W$. coagulans extract and morphine on spermatogenesis in rats.

\section{EXPERIMENTAL}

\section{Collection of plants}

The roots of Withania coagulans were collected in Iranshahr County, Sistan and Baluchestan of province, Iran, in May 2013. A voucher specimen was deposited in a herbarium of the ResearchInstitute of Isfahan Forests and Rangelands by Dr. Feizi.

\section{Preparation of extract}

The roots of $W$. coagulans were air-dried under shade and ground to fine powder using electric blender, then, $60 \mathrm{gr}$ of root powder were extracted with $200 \mathrm{~mL}$ methanol by soxhlet extraction for $12 \mathrm{~h}$. The residue was vaporized using a rotary evaporator. The dried extracts (8 gr) were stored stored at $4{ }^{\circ} \mathrm{C}$ until used. The extracts were dissolved in phosphate buffered saline and tween and tween 80 , at a 1:4 weight ratio for preparing concentrations of 50,100 $\mathrm{mg} / \mathrm{kg}$ body weight.

\section{Preparation of morphine}

Morphine was prepared in normal saline at doses of 5,10 and $15 \mathrm{mg} / \mathrm{kg}$ body weight of rat.

\section{Animals}

Adult male Wistar rats (200 - 250 g) were obtained from Iran Pasteur Institute and divided into 6 groups of eight animals each (48 rats). They were maintained under controlled temperature $\left(22^{\circ} \pm 1^{\circ} \mathrm{C}\right)$, with $12 \mathrm{~h}$ light/12 $\mathrm{h}$ dark conditions for 1 week before the start of the experiments for adaptation to laboratory conditions. The procedures in this study were carried out in a accordance with the institution's scientific procedures for animals and was approved by the Institutional Animal Care and Use Committee (IACUC) [8]. This study was approved by the Medical Research Ethics Committee of the Islamic Azad University of Falavarjan Branch (approval no. IR.IAU.FALA.REC.1397.025).

The animals were randomly divided into 6 groups ( $n=10$ per group) and received intraperitoneally injection. These groups include control group that received normal saline, morphine treated group (5, 10 and $15 \mathrm{mg} / \mathrm{kg})$, morphine (5, 10 and 15 $\mathrm{mg} / \mathrm{kg}$ ) plus extract $(50 \mathrm{mg} / \mathrm{kg})$, morphine $(5,10$ and $15 \mathrm{mg} / \mathrm{kg}$ ) plus extract $(100 \mathrm{mg} / \mathrm{kg})$, extract treated groups (50 and $100 \mathrm{mg} / \mathrm{kg}$ ), respectively. The animals were treated with morphine (groups $2,3,4$ ) once daily for 8 days (the first 2 days with concentration of 5 , the second 2 days with concentration of 10 and the third 4 days with concentration of $15 \mathrm{mg} / \mathrm{kg}$ ) then, $2 \mathrm{~h}$ after treatment with morphine they were treated with extract (groups 3,4 ) once daily for 6 days to evaluate the therapeutic effect of the extract on morphine disorders [9].

The animals were anesthetized with ketamine injections and blood samples were taken directly from the heart one day after the last injection of extract. The hormones $\mathrm{LH}, \mathrm{FSH}$, testosterone were assayed using autoanalyzer (902 Hitachi Automatic Analyzer, Roche, India). The rats were sacrificed by cervical dislocation and their testes were rapidly removed and testicular tissue was fixed in $10 \%$ formalin, dehydrated in ethanol, cleared in xylene and embedded in paraffin. Sections were prepared and then stained with Hematoxylin-Eosin (H\&E) for observe of testicular tissue disorders and counting of different cells (spermatogonium, spermatocyte I and spermatide) (Olympus, Japan). To determine 
the number of sperms in the epididymis, the epididymis tail was removed. Then, for the release of the sperms, the epididymis tail was cut into $2 \mathrm{ml}$ of $37{ }^{\circ} \mathrm{C}$ physiological serum and sperms were diluted to $(1: 20)$ with normal saline. Finally, $10 \mu \mathrm{l}$ was placed on a neobar lam, and the total number of sperms as well as the percentage of sperm motility was counted.

\section{Statistical analysis}

All data are presented as mean \pm SD. The statistical comparisons were done by one-way ANOVA test by SPSS 18 software. $P<0.05$ was considered statistically significant.

\section{RESULTS}

According to results from this study, no significant changes were observed in levels of $\mathrm{LH}, \mathrm{FSH}$ and testosterone in treated groups with extract and morphine. While, the numbers of spermatocytes, spermatids, epididymal sperm density and percentage of sperm motility decreased significantly in group that received morphine alone. Moreover, morphine plus extract $50 \mathrm{mg} / \mathrm{kg}$ let to a significant reduction of spermatocyte; also, extract $50 \mathrm{mg} / \mathrm{kg}$ (group 5) alone, reduced the numbers of spermatogonium. The groups that received morphine plus extract 100 and extract 100 alone showed a significant reduction of spermatogonium, spermatocyte, spermatid, epididymal sperm density and percentage of sperm motility (Table 1).

Histological studies showed that the testicular tissue was normal in the control group. However, the testicles in treated animals with $W$. coagolans extract and morphine showed significantly histopathological alterations. These alterations were included spermatogenesis disorder, reduction of cell types density (spermatogonium, spermatocyte and spermatide), destruction leydig tissue, cell apoptosis, incomplete cell division and the abnormal cells. These changes were more in the groups treated with morphine, morphine plus extract $100 \mathrm{mg} / \mathrm{kg}$ and extract 100 $\mathrm{mg} / \mathrm{kg}$ compared to other groups (Figure 1).

\section{DISCUSSION}

According to the results of this study, the levels of $\mathrm{LH}, \mathrm{FSH}$ and testosterone did not change in treated groups. While $W$. coagolans extract led to significant reduction of cells types whereas $W$. including (spermatogonium, spermatocyte and spermatid). Also, there was a significantly decrease in the density of epididymal sperms and their mobility.

In the present study, the destructive effects of extract on spermatogenesis, may be due to interference of withanolides in the function of hormones and pituitary-gonadal axis. On the other hand, glycoalkaloids are nitrogen containing secondary metabolites that are found in plants of Solanaceae family that its concentration depends on the species and parts of plant; these glycoalkaloids has an important role in plant defense mechanisms that has toxic effects on organs in high concentrations mainly due to their anticholinesterase activity and cell membranes disruption. Solasodine compounds that are found in Solanaceae family and synthesized as glycoalkaloid and are a mediator in synthesis of steroids. This compound has many properties such as anti-spermatogenesis [10].

W. somnifera stimulates the growth of axons and dendrites and causes a state of tranquility [11]. In addition, the roots of this plant increases libido, sperm count, ovarian weight and folliculogenesis. This plant prevents the formation of ROS in infertile men [11].

Table 1: Effects of Withania coagulans extract and morphine on cells number during spermatogenesis and epididymal sperm density and motility (One Way ANOVA)

\begin{tabular}{|c|c|c|c|c|c|c|c|}
\hline Parameter & Control & Morphine & $\begin{array}{l}\text { Morphine- } \\
\text { extract } \\
(50 \mathrm{mg} / \mathrm{ml})\end{array}$ & $\begin{array}{l}\text { Morphine- } \\
\text { extract } \\
(100 \mathrm{mg} / \mathrm{ml})\end{array}$ & $\begin{array}{l}\text { Plant } \\
\text { extract } \\
(50 \mathrm{mg} / \mathrm{ml})\end{array}$ & $\begin{array}{l}\text { Plant extract } \\
(100 \mathrm{mg} / \mathrm{ml})\end{array}$ & $P$-value \\
\hline Spermatogonium & $54.75 \pm 9.82$ & $42.50 \pm 8.91$ & $\begin{array}{l}42.37 \pm 16.6 \\
5\end{array}$ & $33.75 \pm 15.15^{*}$ & $27.87 \pm 18.86$ & $38.12 \pm 15.51^{*}$ & $\begin{array}{l}p<0.05 \\
F=3.144\end{array}$ \\
\hline Spermatocyte & $58.87 \pm 12.60$ & $\begin{array}{l}36.50 \pm 19.58 \\
\text { (C) }\end{array}$ & $\begin{array}{l}22.62 \pm 13.6 \\
6()\end{array}$ & $27.87 \pm 8.52 @$ & $47.00 \pm 6.82$ & $36.25 \pm 17.03 @$ & $\begin{array}{l}p<0.001 \\
F=7.255\end{array}$ \\
\hline Spermatid & $153.87 \pm 33.90$ & $\begin{array}{l}77.62 \pm 38.68 \\
\Omega\end{array}$ & $\begin{array}{l}137.87 \pm 27 \\
49\end{array}$ & $62.50 \pm 37.81 \Omega$ & $\begin{array}{l}131.37 \pm 14.6 \\
0\end{array}$ & $81.25 \pm 40.51 \Omega$ & $\begin{array}{l}p<0.001 \\
F=10.409\end{array}$ \\
\hline $\begin{array}{l}\text { Epididymal sperm } \\
\text { density }\end{array}$ & $43150 \pm 2500$ & $\begin{array}{l}17956 \pm 2351 \\
\Omega\end{array}$ & $\begin{array}{l}39780 \pm 278 \\
0\end{array}$ & $18547 \pm 1740 \Omega$ & $41890 \pm 3640$ & $18970 \pm 1780 \Omega$ & $\begin{array}{l}p<0.001 \\
F=5.348\end{array}$ \\
\hline $\begin{array}{l}\text { Sperm motility } \\
(\%)\end{array}$ & $72.3 \pm 7.8 \%$ & $\begin{array}{l}35.54 \pm 4.1 \% \\
\Omega\end{array}$ & $\begin{array}{l}69.12 \pm 8.65 \\
\%\end{array}$ & $38.78 \pm 5.6 \% \Omega$ & $70.4 \pm 6.7 \%$ & $33.5 \pm 4.9 \% \Omega$ & $\begin{array}{l}p<0.001 \\
F=9.187\end{array}$ \\
\hline
\end{tabular}

*Significant reduction in the number of spermatogonium $(p<0.05)$; CSignificant reduction in the number of spermatocyte $(p<0.001) ; \Omega$ Significant reduction in the number of spermatide $(p<0.001)$ 

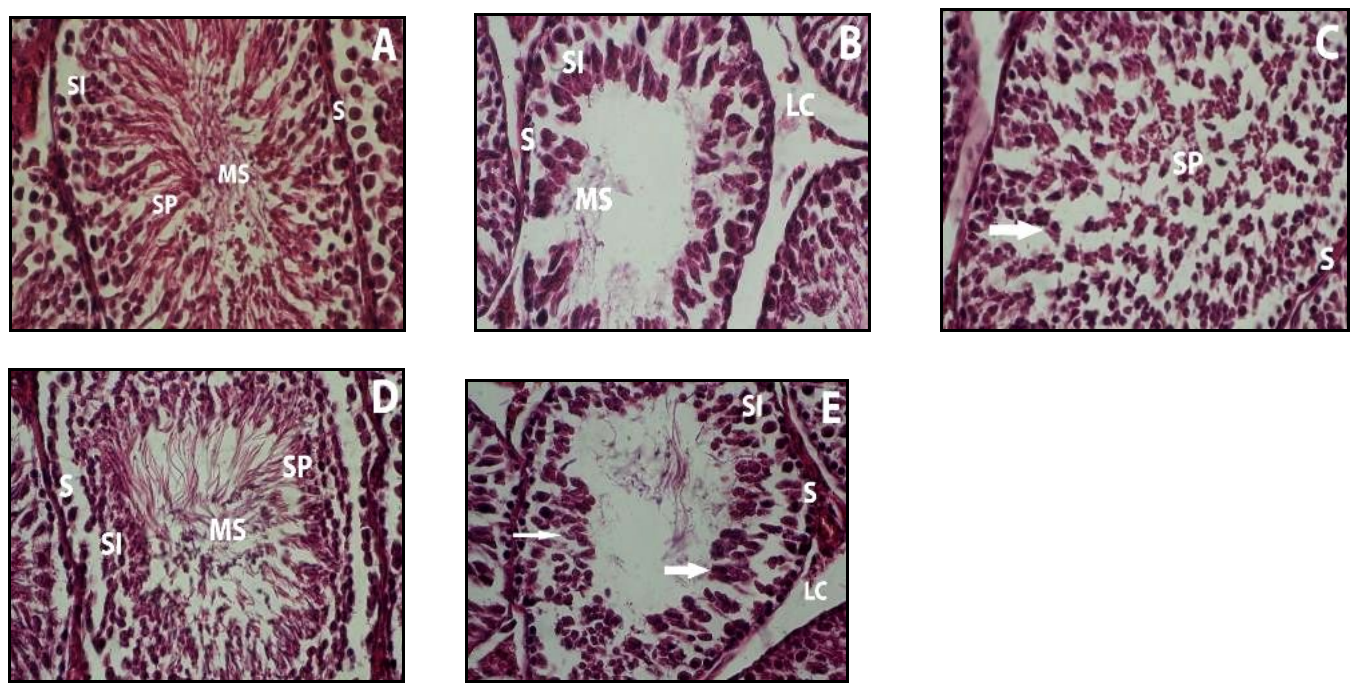

Figure 3: Sections of the testicular tissue in control and treated groups (with morphine plus extract $100 \mathrm{mg} / \mathrm{kg}$ and extract $100 \mathrm{mg} / \mathrm{kg}$ ) of rats. (A) control group the seminiferous tubules and cells types (spermatogonium, spermatocyte and spermatide) density are normal, (B) the destruction of leydig cells, reduction of cells types and mature sperms, (C) the lack of mature sperm formation, cells apoptosis and degeneration (arrow), (D) the reduction of mature sperms, (E) the severe apoptosis (thin arrow), abnormal division of cells (thick arrow). (S, spermatogonium; SI, spermatocyte; SP, spermatid; MS, mature sperm; LC, lydig cells) (×400)

W. somnifera root powder ( $5 \mathrm{~g} /$ day) for 3 months, decreased FSH and also increased levels of LH, testosterone and sperm count in infertile men. The major effects of this plant include reducing oxidative stress, hormone levels and improves detoxification processes in body [12]. Moreover, $W$. somnifera aqueous extract induces some changes in hypophysial gonadotropins and thus increases sperm [13]. The powder of this plant $(6.25 \%)$ was given to diabetic rats for 4 weeks and caused increase the levels of LH, testosterone and progesterone, while, FSH level decreased. This plant probably has excitatory effects on the $\mathrm{LH}$ and luteal cells and inhibitory effects on FSH [13].

The effect of $W$. somnifera on sex hormones levels is probably via inhibition of oxidative stress and most of the pharmacological activity of this plant is related to two main withanolides (withaferin A, withanolide D)[14]. In fact, withanolides induces some chemical compounds that can affect the metabolic activity [18]. In another study, $W$. somnifera reduced malondialdehyde (MDA) and testicular disorders induced by galactose and increased the sperm count [14]. Moreover, methanolic extract of this plant eliminates the disorders caused by acephate insecticide on $\mathrm{LH}, \mathrm{FSH}$, testosterone and testis tissue [16]. According to the studies, ROS is generated by Sertoli cells in the testis that the controlled amount of ROS is necessary for capacitation, spermiogenesis and acrosome reaction. In a study on infertile men, sperm apoptosis and high concentrations of ROS were observed, that $W$. somnifera reduced these abnormalities. As a result, $W$. somnifera can be improved semen quality by reducing cell death and oxidative stress [17]. The extract of this plant $(47 \mathrm{mg} / 100 \mathrm{~g})$ caused testicular development and spermatogenesis in immature rats for 6 days that this was associated with increased LH [18].

According to studies on different species of Withania, various extracts of this plant have reinforcing effects on spermatogenesis that is probably through inhibition of ROS, reduce stress, occupy the sex hormone receptors and effect on the pituitary-gonadal axis. Nevertheless, in some cases, the lowering effects of $\mathrm{FSH}$, testosterone and antispermatogenesis properties of this extract may be due to the presence of glycoalkaloid compounds or effect on receptors, so that these results are consistent with our findings.

Previous research investigated the effect of Genistein on reproductive in morphine-treated mice and showed that genistein and genistein plus morphine significantly increased motility, morphology, count, viability of sperm cells, seminiferous tubules diameter, germinal thickness, testosterone, $\mathrm{LH}$ and FSH. It seems that genistein prevent morphine- induced adverse effects on sperm parameters. The results of the current research confirmed the results of other studies which showed antioxidants can increase sperm motility [19]. Our results corroborated the findings of other researchers who found alkaloids and flavonoids 
could increase testosterone level through increasing LH [17]. However, the findings were in contrast with results of other researchers who demonstrated isoflavonid as a stopper of testosterone generation [20].

The findings of the study of other researchers showed a decrease in testosterone level in high concentrations of phytoestrogens [20], which is in line with the results of current study obtained in groups receiving high concentrations of Withania coagolans extract (100 mg/kg).

\section{CONCLUSION}

The findings of the present study indicate that a higher dose of Withania coagolans extract (100 $\mathrm{mg} / \mathrm{kg}$ ) can have a reverse effect on reproductive parameters. Since Withania coagolans extract affects pituitary-gonadal axis and exert the negative effects on testis tissue and secretion of sexual hormones in higher doses, therefore, it seems that alkaloids and flavonoids exert both agonistic and antagonistic effects on the studied tissue depending on the dose. Moreover, the lower dose of Withania coagolans extract (50 $\mathrm{mg} / \mathrm{kg}$ ) seems to enhance spermatogenesis parameters and protects against the damaging effects of morphine.

\section{DECLARATIONS}

\section{Acknowledgement}

The authors would like to thank the Department of Biology, Islamic Azad University, Falavarjan Branch for their cooperation and support.

\section{Conflict of interest}

No conflict of interest is associated with this work.

\section{Contribution of authors}

We declare that this work was done by the authors mentioned in this article and all liabilities regarding claims relating to the content of this article will be borne by the authors. Leila Amjad conceived and designed the study. Ali noori collected, analysed and wrote the manuscript with the collaboration of Fereshteh Yazdani. All authors read and approved the manuscript for publication.

\section{Open Access}

This is an Open Access article that uses a funding model which does not charge readers or their institutions for access and distributed under the terms of the Creative Commons Attribution License (http://creativecommons.org/licenses/by/ 4.0) and the Budapest Open Access Initiative (http://www.budapestopenaccessinitiative.org/rea d), which permit unrestricted use, distribution, and reproduction in any medium, provided the original work is properly credited.

\section{REFERENCES}

1. Abbasi zadeh Z, Kesmati M, Fathi Moghadam $H$, Zadkarami MR. Study of effect of Matricaria recutita extract on morphine withdrawal signs in the presence and following partial electrical lesion of paragigantocellularis nucleus in adult male rats. Iran $\mathrm{J}$ Pharm Res 2008; 21: 351-359.

2. Ghowsi $M$, yousofvand $N$, Pourmotabbed $A$. Effects of morphine dependency and its abstinence on serum concentrations of sex hormones and reproductive system in male rats. J Kermanshah Univ Med Sci 2013; 1: 8-15.

3. Kretser DM, Loveland KL, Meinhardt A, Simorangkir D, Wreford N. Spermatogenesis. Human Reprod 1998; 13 : 1-8.

4. Ogiwara k, Fujimori CH, Rajapakse S, Takahashi T. Characterization of luteinizing hormone and luteinizing hormone receptor and their indispensable role in the ovulatory process of the medaka. Plos One 2013; 8: 114.

5. Assaee R, Pajhohi N, Shirkhani Y, Tarrahi M, Zahedi AsI $A$. The effect of parental morphine addiction on rat's reproduction rate and pituitary-gonadal axis hormone profile of their adult. Int $J$ Endocrinol Metab 2008; 10 : 51-57.

6. Castro ACS, Berndtson WE, Cardoso FM. Plasma and testicular testosterone levels, volume density and number of leydig cells and spermatogenic efficiency of rabbits. Braz J Med Biol Res 2002; 35: 493-498.

7. Gupta PC. Withania coagulans Dunal - An overview. Int J Pharm Sci Rev Res 2012; 12: 68-71.

8. Silverman J. Chapter 3-The institutional animal care and use committee. Research Regulatory Compliance. USA; Elsevier; 2015; pp 41-78.

9. Karami M, Gohari AR, Ebrahimzadeh MA. Effect of Withania coagulans root extraction the withdrawal syndrome in mice. Pharmacol 2006; 3: 166-171.

10. Patel K, Singh RB, Patel DK. Medicinal significance, pharmacological activities, and analytical aspects of solasodine: a concise report of current scientific literature. J Affect Disord 2013; 2: 92-98.

11. Umadevi $M$, Rajeswari $R$, Sharmila Rahale $C$, Selvavenkadesh S, Pushpa R, Sampath Kumar KP, Bhowmik D. Traditional and medicinal uses of Withania somnifera. Pharm Innov J 2012; 1: 102-110.

12. Ambiye VR, Langade D, Dongre S, Aptikar P, Kulkarni M, Dongre $A$. Clinical evaluation of the spermatogenic activity of the root extract of Ashwagandha (Withania 
somnifera) in oligospermic males: A pilot study. Evid Based Complement Alternat Med 2013; 2013: 1-6.

13. Kiasalari Z, Khalili M, Aghaei M. Effect of Withania somnifera on levels of sex hormones in the diabetic male rats. Int J Reprod BioMed 2009; 7: 163-168.

14. Belal NM, El-Metwally EM, Salem IS. Effect of dietary intake Ashwagandha roots powder on the levels of sex hormones in the diabetic and non-diabetic male rats. World J Dairy Food Sci 2012; 7: 160-166.

15. Patil RB, Vora ShR, Pillai MM: Protective effect of spermatogenic activity of Withania somnifera (Ashwagandha) in galactose stressed mice. Annal Biol Res 2012; 3: 4159-4165.

16. Dut Jasuja N, Sharma P, Joshi SC. Ameliorating effect of Withania somnifera on acephate administered male albino rats. Afr J Pharm Pharmacol 2013; 7: 1554-1559.

17. Shukla KK, Mahdi AA, Mishra V, Rajender S, Narain Sankhwar S, Patel D, Das M. Withania somnifera improves semen quality by combating oxidative stress and cell death and improving essential metal concentrations. Reproductive Bio Medicine 2011; 22: 421- 427.

18. Abdel-Magied EM, Abdel-Rahman HA, Harraz FM. The effect of aqueous extracts of Cynomorium coccineum and Withania somnifera on testicular development in immature wistar rats. J Ethnopharmacol 2001; 75: 1-4.

19. Jalili C, Ahmadi S, Roshankhah S, Salahshoor MR. Effect of genistein on reproductive parameter and serum nitric oxide levels in morphine-treated mice. Int Reprod BioMed 2016; 14(2): 95-1012.

20. Bae M, Woo M, Kusuma IW, Arung ET, Yang CH, Kim YU. Inhibitory effects of isoflavonoids on rat prostate testosterone 5a-reductase. J Acupunct Meridian 2012; 5: 319-322. 